\title{
The Impact of Surface Treatment on the Structure and Chemistry of Protective Oxide-Scale in High-Temperature Oxidation-Resistant Nickel Alloys
}

Stephen House, Henry Ayoola, John Lyons, Meng Li, Bingtao Li, Judith Yang, Wissam Saidi and Brian Gleeson

University of Pittsburgh, Pittsburgh, Pennsylvania, United States

High-temperature oxidation-resistant alloys often have finishes - such as polishing or vapor-blasting applied to their exposed surfaces for aesthetic or practical reasons, which introduce deformation into the surface grain structure. Upon heating, a region of recrystallized grain structure can be formed at the surface.[1] The degree and depth of the recrystallized zone depends on the type of surface finishing treatment, which in turn affects the extent of imposed surface deformation. Previous studies of Ni-Al and $\mathrm{Ni}-\mathrm{Al}-\mathrm{Cr}$ alloys have shown that the surface finish as well as surface recrystallization have a direct effect on the establishment of an oxide scale during oxidation. [2] The effect is believed to result from a balance between the oxide nucleation on the roughened surface and the formation of short-circuit diffusion paths in the recrystallized zone. The recrystallization creates a finer grain structure than the bulk alloy, the added grain boundaries of which provide paths for faster diffusion of scale-forming species.[2]

Haynes $214 \AA$ is a high-temperature oxidation-resistant nickel-aluminum-chromium-iron alloy that is known to form adherent alumina scales above $955^{\circ} \mathrm{C}$. Below this temperature, however, it can form either an alumina, chromia, or a combined oxide scale. Its most beneficial corrosion-resistant properties are achieved by the formation of an alumina scale. Thus, 214 alloy provides an ideal system to study the effect of surface finish on oxide scale formation. In this work, the effect of surface finishing (polishing or vapor blasting) on oxide scale formation was studied. Structural and chemical properties of the oxide scale, as well as surface and subsurface structure of the alloy resulting from deformation and oxidation processes, were investigated.

Samples of Alloy 214, cut from the same stock, were polished with either 500-grit paper, 1200-grit paper, or vapor-blasted with 300 mesh glass beads. The surface-finished samples were then oxidized in air at $800^{\circ} \mathrm{C}$ for 2 hours. Topographic imaging and surface roughness measurements were performed using atomic force microscopy (AFM) and scanning electron microscopy (SEM). Cross-sectional samples were prepared for characterization using a dual-beam focused ion beam (FIB)-SEM. The structure of crosssectional samples was characterized using SEM and high-resolution TEM. Chemical composition was determined using energy-dispersive X-ray spectroscopy in an aberration-corrected scanning TEM (STEM-EDS).

FIB cross-sections of the (a) 500-grit polished, (b) 1200-grit polished, and (c) vapor-blasted 214 samples after $2 \mathrm{~h}$ oxidation are shown in Figure 1. The cross-sections reveal distinct recrystallization zones in all three samples: a $\sim 1.9 \mu \mathrm{m}$ thick zone in the 500-grit polished sample, and a thinner $\sim 0.7 \mu \mathrm{m}$ thick zone in the 1200-grit polished and vapor-blasted samples. The grains below the recrystallized zone in the polished samples are much larger at up to $10 \mu \mathrm{m}$ in size, consistent with the bulk grain size. The vapor-blasted sample on the other hand exhibited a vastly different grain structure; the grains beneath the recrystallization zone were significantly smaller and varied in size compared to the recrystallized grains. This unusual grain structure was observed throughout the full depth of the cross-sectional sample $(>10$ $\mu \mathrm{m}$ deep), indicative of more severe deformation. Interestingly, previous research has demonstrated that blasting can modify the grain structure up to depths greater than $100 \mu \mathrm{m}$ into the bulk [3]. 
The depth of the recrystallization region was observed to correlate with the thickness of the subsequent oxide scale. The 500-grit polish promoted a thicker $~ 300 \mathrm{~nm}$ oxide scale, whereas the 1200-grit and vaporblasted finishes showed a thinner $\sim 100 \mathrm{~nm}$ oxide scale. This relationship was further reinforced by the fact that a depletion of the oxide scale's primary cation was limited to the recrystallization region; below this layer, the composition was constant extending into the bulk. A potential correlation between the surface roughness and extent of recrystallization was also observed, with the 500-grit surface possessing substantially higher RMS surface roughness $(491.8 \mathrm{~nm})$ than the 1200 -grit or vapor-blasted $(159.5 \mathrm{~nm}$ and $69.4 \mathrm{~nm}$ - inside the bead craters - respectively).

Faster oxide growth kinetics on the 500-grit polished sample may be explained by the formation of a $\mathrm{Cr}_{2} \mathrm{O}_{3}$-rich scale on this sample; whereas, an $\mathrm{Al}_{2} \mathrm{O}_{3}$-rich scale formed on the other two samples. This is verified in Figure 2, which shows the EDS maps from the FIB cross-sections. The formation of a $\mathrm{Cr}_{2} \mathrm{O}_{3}-$ rich scale on the 500-grit sample suggests faster diffusion of $\mathrm{Cr}$ than $\mathrm{Al}$ along the recrystallized grain boundaries, a hypothesis supported by the observation of Cr-rich precipitates nucleated along the grain boundaries and intersections. In the case of the 1200-grit polished and vapor-blasted samples, the middle region of the $\mathrm{Al}_{2} \mathrm{O}_{3}$ scales contained a chromium-enriched layer, suggesting that a $\mathrm{Cr}_{2} \mathrm{O}_{3}$-rich scale formed first, that was subsequently overtaken by $\mathrm{Al}_{2} \mathrm{O}_{3}$ formation and growth. The evolutionary steps in such a scaling process are still being investigated. Studies are also ongoing to further understand why alumina forms instead of chromia in the finer-finished samples and how the additional phase segregations (notably, silica) observed at the surface of certain samples before or after oxidation may arise from the finishing treatment and impact scale growth. A more complete understanding of the role of surface finish on oxide formation will enable the tailoring of surface finishing procedures to obtain desired protective oxide properties.[4]

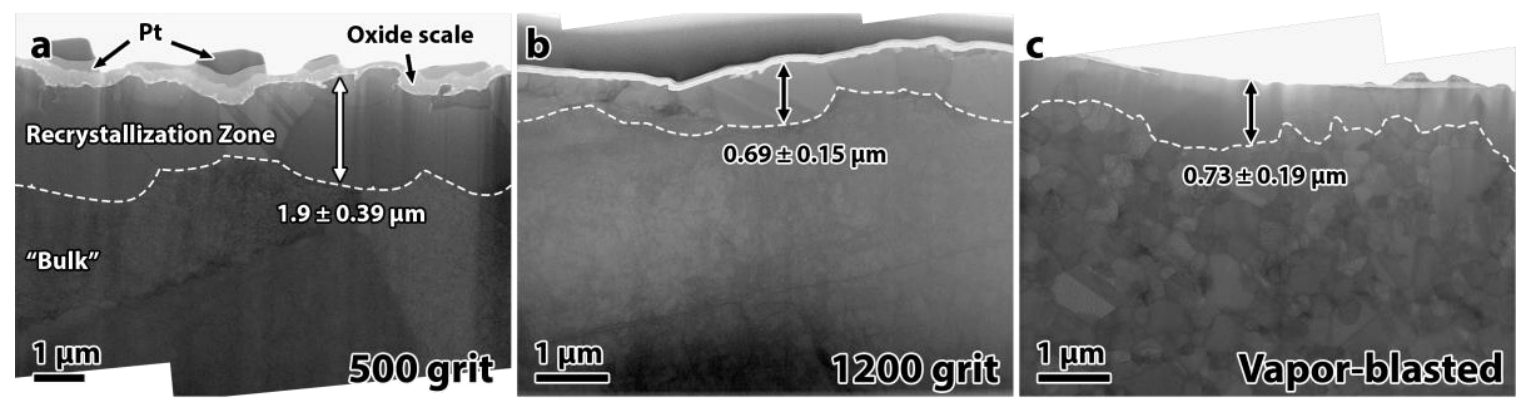

Figure 1. TEM images of the cross-sections of the (a) 500 grit polished, (b) 1200 grit polished, and (c) vapor-blasted alloy 214 samples after oxidation at $800{ }^{\circ} \mathrm{C}$ for 2 hours in air. The lower boundary of the recrystallization zone in each sample is marked by a dashed line. The platinum on the surface is deposited during FIB sample preparation to protect the sample surface from ion beam damage. 


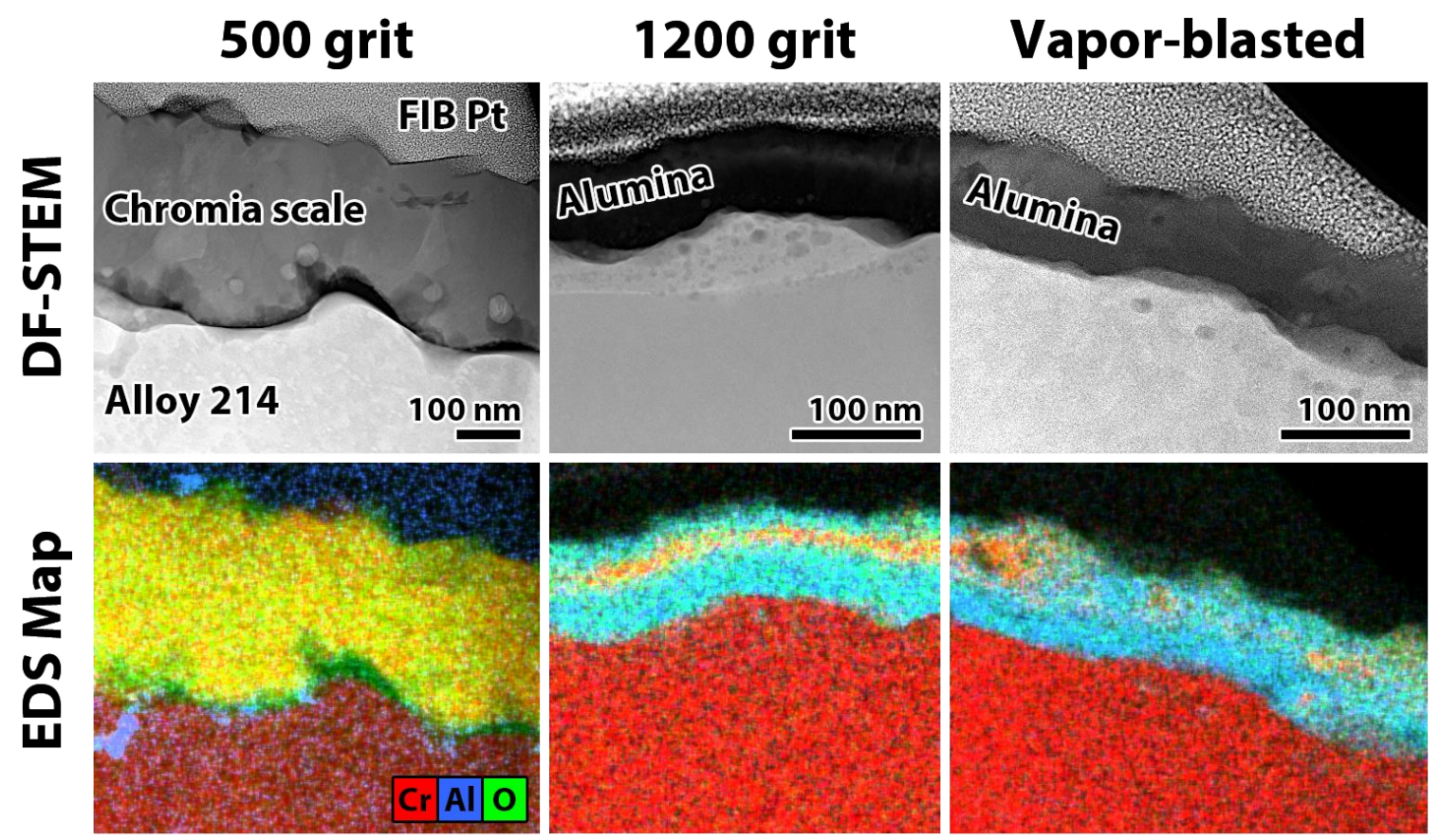

Figure 2. Dark-field STEM images of the cross-sections of the 500 grit polished, 1200 grit polished, and vapor-blasted alloy 214 samples from Figure 1 and the corresponding EDS elemental maps for $\mathrm{Cr}$ (red), $\mathrm{Al}$ (blue), and $\mathrm{O}$ (green). The platinum on the surface was deposited during FIB sample preparation to protect the sample surface from ion beam damage.

\section{References}

1. C.S. Giggins and F.S. Pettit, Trans. AIME. 245 (1969) pp.2509-2516

2. Y. Kang, PhD Dissertation, University of Pittsburgh (2016)

3. M. Multigner, E. Frutos, J.L. González-Carrasco, J.A. Jiménez, P. Marín, J. Ibáñez, Materials Science and Engineering: $C, 29$ (2009)

4. We acknowledge funding from the US National Science Foundation [CHE-1534630 and DMR1508417]. This research used resources of the Environmental TEM Catalysis Consortium (ECC), which is supported by the University of Pittsburgh and Hitachi High Technologies. 